\title{
Antiviral activity of shikonin ester derivative PMM-034 against enterovirus 71 in vitro
}

\author{
Y. Zhang ${ }^{1,2 *}$, H. Han ${ }^{1 *}$, L. Sun ${ }^{3 *}$, H. Qiu ${ }^{1}$, H. Lin ${ }^{1}$, L. Yu ${ }^{2}$, W. Zhu ${ }^{2}$, J. Qi ${ }^{1}$, R. Yang ${ }^{1}$, Y. Pang ${ }^{1}$, \\ X. Wang ${ }^{1}$, G. $\mathrm{Lu}^{1}$ and $\mathrm{Y}$. Yang \\ ${ }^{1}$ State Key Laboratory of Pharmaceutical Biotechnology, NJU-NJFU Joint Institute of Plant Molecular Biology, \\ Nanjing University, Nanjing, China \\ ${ }^{2}$ Suzhou Industrial Park Center for Disease Control and Prevention, Suzhou, China \\ ${ }^{3}$ College of Agriculture, Nanjing Agricultural University, Nanjing, China
}

\begin{abstract}
Human enterovirus 71 (EV71) is the major causative agent of hand, foot, and mouth disease (HFMD), particularly in infants and children below 4 years of age. Shikonin is a bioactive compound with anti-inflammatory, antiviral, and antibacterial activities derived from the roots of the Chinese medicinal herb Lithospermum erythrorhizon. This study aimed to examine the antiviral activity of PMM-034, a shikonin ester derivative, against EV71 in rhabdomyosarcoma (RD) cells. Cytotoxicity of PMM-034 on RD cells was determined using WST- 1 assay. Dose- and time-dependent effects of PMM-034 on EV71 replication in RD cells were determined using plaque reduction assay. mRNA expression levels of EV71/VP1 and pro-inflammatory cytokines (IL-1 $\beta$, IL-6, IL-8, and TNF- $\alpha$ ) were determined by real-time RT-PCR, and EV71/VP1 and phospho-p65 protein expressions were determined by western blot analysis. PMM-034 exhibited only weak cytotoxicity against RD cells. However, PMM-034 exhibited significant antiviral activity against EV71 in RD cells with $50 \%$ inhibitory concentration of $2.31 \mu \mathrm{g} / \mathrm{mL}$. The VP1 mRNA and protein levels were significantly reduced in cells treated with PMM-034. Furthermore, relative mRNA expression levels of IL-1 $\beta$, IL-6, IL-8, and TNF- $\alpha$ significantly decreased in the cells treated with PMM-034, while the phospho-p65 protein expression was also significantly lower in the treated cells. These results indicated that PMM-034 suppressed the expressions of proinflammatory cytokines in RD cells, exhibiting antiviral activity against EV71, as evidenced by the reduced VP1 mRNA and protein levels in PMM-034-treated cells. Thus, PMM-034 is a promising candidate for further development as an EV71 inhibitor.
\end{abstract}

Key words: EV71; VP1; Shikonin ester derivatives PMM-034; Rhabdomyosarcoma cells; NF-kB

\section{Introduction}

Hand, foot, and mouth disease (HFMD) is a common viral infection that commonly affects children below the age of 4 years (1). Human enterovirus 71 (EV71) belongs to the Enterovirus genus of the family Picornaviridae and causes sporadic outbreaks of HFMD. EV71 infection targets the central nervous system (CNS) (2). Once EV71 infects the CNS, a patient can die rapidly from severe complications including encephalitis and pulmonary edema (3). Recently, several consecutive EV71 epidemics have been reported in the Asia-Pacific region and no effective treatment for this infection exists. Selection of resistant viruses after treatment with antiviral drugs is inevitable (4), and while resistant viral strains have increased in recent years, only a few antiviral drugs have been approved for clinical use (5). The pace of pathogen resistance has exceeded the development of new antiviral drugs. Therefore, there is an urgent need to develop new effective antiviral compounds (4) to meet the growing need and combat resistance to existing antiviral drugs.

Signal transduction pathways are essential for normal viral immunity and for virus replication. Viral infections induce the production of pro-inflammatory cytokines and chemokines. A previous study has shown that excessive pro-inflammatory cytokine and chemokine responses were induced in human monocyte-derived macrophages, and interleukin (IL)-1 $\beta$, IL-6, IL-8, and TNF- $\alpha$ levels, but not IFN- $\alpha$ and $\gamma$ levels, were increased in EV71-infected patients (6). The NF-kB complex is activated in response to viral and bacterial infections, and the binding of the virion to its receptor can trigger membrane-proximal sig-

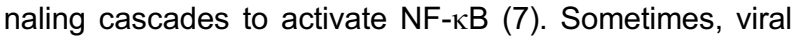

Correspondence: Y. Yang: <yangyh@nju.edu.cn> | G. Lu: <guihua.lu@nju.edu.cn> |X. Wang: <wangxm07@nju.edu.cn>

${ }^{*}$ These authors contributed equally to this study.

Received April 9, 2017 | Accepted July 3, 2017 
products such as dsRNA and viral proteins can trigger NF- $\kappa \mathrm{B}$ activation (8).

Several herbal prescriptions of traditional Chinese medicine (TCM) have been used to manage endemic infections due to their antiviral activity, for example, directly inhibiting or inactivating viruses, or improving the host immune system (9-11). Historically, root extracts obtained from the Chinese medicinal herb $L$. erythrorhizon have been used to treat burns, inflammation, trauma, and ulcers (12). Several studies have demonstrated that $L$. erythrorhizon has strong inhibitory activity towards neuraminidase and exhibits antiviral effects [i.e., against influenza $A$ (H1N1) virus] by decreasing the viral reproduction and cytopathic effects (CPE) on virus-infected cells (13). Shikonin is an important naphthoquinone natural product derived from the roots of $L$. erythrorhizon (14). Shikonin exhibits a broad range of pharmacological activities including anti-oxidant, anti-cancer, anti-inflammatory and antibacterial effects $(15,16)$. Shikonin may also exert antiviral activity, and it has been found to exhibit anti-human immunodeficiency virus-1 (HIV-1) and adenovirus activities $(7,17)$. Recent research on shikonin has shifted to its derivatives (18), of which PMM-034 is one type (Figure 1). However, the antiviral effect of PMM-034 on EV71 infection remains unclear.

Here, we evaluated the extent to which PMM-034 could inhibit EV71 replication, and then assessed its effect on EV71/NP1 mRNA and protein expressions in rhabdomyosarcoma (RD) cells in vitro. Furthermore, we explored the stage in the replication cycle at which PMM-034 inhibits EV71 and assessed the anti-inflammatory activity of PMM-034 on EV71-induced inflammation in vitro.

\section{Material and Methods}

\section{Cells and viruses}

RD cells were purchased from the American Type Culture Collection (USA) and cultured in Dulbecco's modified Eagle's medium (DMEM; Gibco, USA) with $10 \%$ fetal bovine serum (FBS; Gibco). The cell culture plates were incubated in a humidified incubator containing $5 \% \mathrm{CO}_{2}$ at $37^{\circ} \mathrm{C}$.

EV71 was provided by the Suzhou Centre for Disease Prevention and Control (China). Finally, virus particles<smiles>CC(C)=CC[C@H](OC(=O)CCc1c[nH]c2ccccc12)C1=CC(=O)c2c(O)ccc(O)c2C1=O</smiles>

Figure 1. Chemical structure of PMM-034. were amplified using RD cells, and the virus titer was determined by a plaque reduction assay using RD cells.

\section{Compounds}

Shikonin ester derivatives were synthesized by our lab (19-21), and PMM-034 was dissolved in dimethyl sulfoxide (DMSO) for in vitro studies.

\section{Cytotoxicity assay}

Cytotoxicity of PMM-034 against RD cells was determined using cell viability assay in 96-well plates with cells cultured to $80-90 \%$ confluence (approximately $5 \times 104$ cells/well). The cells were treated with various concentrations of PMM-034 dissolved in DMSO (0, 2.5, 5 , 10 , and $20 \mu \mathrm{g} / \mathrm{mL}$ ) for $48 \mathrm{~h}$, and then cell viability was assayed using WST-1 (Beyotime, China). Briefly, $10 \mu \mathrm{L}$ of WST-1 solution was added to the cells and the suspension was incubated at $37^{\circ} \mathrm{C}$ for $2 \mathrm{~h}$. Medium without cells was used as the blank control. Absorbance was measured at a wavelength of $450 \mathrm{~nm}$ using an AMR-100 Microplate Reader (ThermoRui-OS, USA). Cell viability was calculated using the following formula: Cell viability $(\%)=($ absorbance (Ab)experimental group - Abblank control) / (Abnegative control - Abblank control) $\times 100 \%$. The half-maximal cytotoxic concentration (CC50) was defined as the concentration that reduced the $\mathrm{Ab}$ of PMM-034-treated cells to $50 \%$ the $\mathrm{Ab}$ of negative control (untreated cells) (22).

\section{Plaque reduction assay}

RD cells $\left(3 \times 10^{5}\right.$ cells/well) were seeded into 6-well plates and cultured to $80 \%$ confluence. After EV71 [80 plaque-forming units (pfu)/well] were incubated with RD cells to allow absorption for one hour at $37^{\circ} \mathrm{C}$, the culture supernatants were replaced with fresh DMEM containing $1-3 \%$ FBS and $1.5 \%$ methyl cellulose, and then cultured for an additional $96 \mathrm{~h}$ at $37^{\circ} \mathrm{C}$ in the presence of $5 \% \mathrm{CO}_{2}$. The cells were then washed with phosphate-buffered saline, fixed with $4 \%$ paraformaldehyde, stained with $5 \%$ crystal violet for $15 \mathrm{~min}$, and then washed in running water. The plaques were counted under an inverted microscope (Nikon, TS100, Japan), and the virus titer $(\mathrm{pfu} / \mathrm{mL})$ was determined. Inhibition rate (\%) was calculated as follows: [(mean number of plaques in the untreated group) - (mean number of plaques in the experimental group)] / (mean number of plaques in the untreated group) $\times 100(23)$.

Time-dependent effect of PMM-034 on EV71 replication in $R D$ cells. RD cells $\left(3 \times 10^{5}\right.$ cells/well) were seeded and incubated in the wells of 6 -well plates. RD cell monolayers were infected with EV71 at 80 pfu/well. After incubation for $1 \mathrm{~h}$ to facilitate absorption, culture supernatants were replaced with fresh DMEM containing $1-3 \%$ FBS. Then, $10 \mu \mathrm{g} / \mathrm{mL}$ PMM-034 was added to the cells at $0,4,8,12,16$, and $24 \mathrm{~h}$ post-infection. Cell supernatants were collected for the viral plaque reduction assay. 
Dose-dependent effect of PMM-034 on EV71 replication in RD cells. RD cells $\left(3 \times 10^{5}\right.$ cells/well) were plated into 6-well culture plates and incubated for $24 \mathrm{~h}$. The medium was then removed and cells were infected with EV71 at 80 pfu/well. After virus absorption for $1 \mathrm{~h}$, the medium was aspirated from the wells to remove unabsorbed virus, and the cells were washed thrice with serum-free DMEM, and treated with different PMM-034 concentrations to test for antiviral activity. Finally, EV71infected cells and culture supernatants were collected $48 \mathrm{~h}$ after infection for the plaque reduction assay.

Quantitative real-time reverse transcription (RT)-PCR

Total RNA was extracted using Trizol (Invitrogen, USA) according to the manufacturer's instructions. The RNA purity and concentration were determined by spectroscopy [Ab260/Ab280] to be 1.8-2.0. RNA was reverse transcribed using a Reverse Transcription System (Promega, USA). Primers for $I L-1, I L-6, I L-8, T N F-\alpha, V P 1$ and $G A P D H$ were designed using Beacon Designer 7.0 and synthesized by Sangon Biotech Company (China; Table 1). Specific mRNAs were quantified by real-time PCR using Fast SYBR Green Master Mix (Invitrogen) in a Bio Rad CFX96 Real-Time System (Bio Rad, USA). Real-time PCR reactions were performed in triplicate in 96-well plates under the following conditions; $15 \mathrm{~s}$ at $95^{\circ} \mathrm{C}$ followed by 40 cycles of $15 \mathrm{~s}$ at $95^{\circ} \mathrm{C}, 30 \mathrm{~s}$ at $65^{\circ} \mathrm{C}$, and $30 \mathrm{~s}$ at $72^{\circ} \mathrm{C}$. GAPDH was used as the internal control. The relative expression levels of the genes were compared with those of GAPDH by the $2^{-\Delta \Delta \mathrm{Ct}}$ method.

\section{Western blot analysis}

Total protein was extracted using radio-immunoprecipitation assay plus phenylmethylsulfonyl fluoride (Solarbio, China) according to the manufacturer's instructions. Protein concentration was determined by the BCA Protein Assay Kit (Thermo, USA). Equal amounts of protein

Table 1. Primers used for real-time PCR.

\begin{tabular}{ll}
\hline Gene & \multicolumn{1}{c}{ Sequence $\left(5^{\prime}-3^{\prime}\right)$} \\
\hline VP1 & F: TGGCAGATGTGATTGAGAG \\
& R: GGCTTGAATGCTGGTA \\
IL-1 $\beta$ & R: ATGATGGCTTATTACAGTGGCAA \\
& F: AGGAGACTTGCCTGGTGAAA \\
IL-6 & R: CAGGGGTGGTTATTGCATCT \\
& F: TTGGCAGCCTTCCTGATTC \\
IL-8 & R: TCTTTAGCACTCCTTGGCAAAC \\
& F: GAGGCCAAGCCCTGGTATG \\
TNF- $\alpha$ & R: CGGGCCGATTGATCTCAGC \\
GAPDH & F: GCACCGTCAAGGCTGAGAAC \\
& R: TGGTGAAGACGCCAGTGGA \\
\hline
\end{tabular}

F: forward; R: reverse.
$(60 \mu \mathrm{g})$ were subjected to sodium dodecyl sulfatepolyacrylamide gel electrophoresis using $10 \%$ gels. Proteins were transferred to nitrocellulose membrane (GE Healthcare, USA). After the transfer, the membranes were blocked with $5 \%(\mathrm{w} / \mathrm{v})$ nonfat dry milk in TBS-T $(10 \mathrm{mM}$ Tris- $\mathrm{HCl}, \mathrm{pH} 8.0,150 \mathrm{mM} \mathrm{NaCl}$ containing $0.1 \% \mathrm{v} / \mathrm{v}$ Tween-20) for at least $1 \mathrm{~h}$. The membranes were then incubated with the following primary antibodies: AntiNorovirus capsid protein VP1 antibodies (ab92976, 1:500; Abcam, UK); phospho-NF-kB/p65 (S536) rabbit antibodies (3013, 1:1000; CST, USA); $\beta$-actin mouse monoclonal antibodies (A1978, 1:3000; Sigma Aldrich, USA) in blocking buffer overnight at $4^{\circ} \mathrm{C}$. After washing thrice with TBST, membranes were incubated with secondary antibodies for $30 \mathrm{~min}$ and detected using an ECL PLUS detection kit (Thermo).

\section{Statistical analysis}

Statistical analyses were conducted using SPSS 17.0 software. Data are reported as means \pm SD from at least three independent experiments performed in triplicate. Statistical significance was evaluated by the Student's $t$-test. $\mathrm{P}<0.05$ was considered to be statistically significant.

\section{Results}

\section{Cytotoxicity of PMM-034 on RD cells}

The results of the WST-1 assay revealed that PMM034 did not significantly affect cell viability at concentrations of $\leqslant 100 \mu \mathrm{g} / \mathrm{mL}$, and its $\mathrm{CC}_{50}$ was $137.9 \mu \mathrm{g} / \mathrm{mL}$. This finding suggested that PMM-034 was only weakly cytotoxic to RD cells (Figure 2).

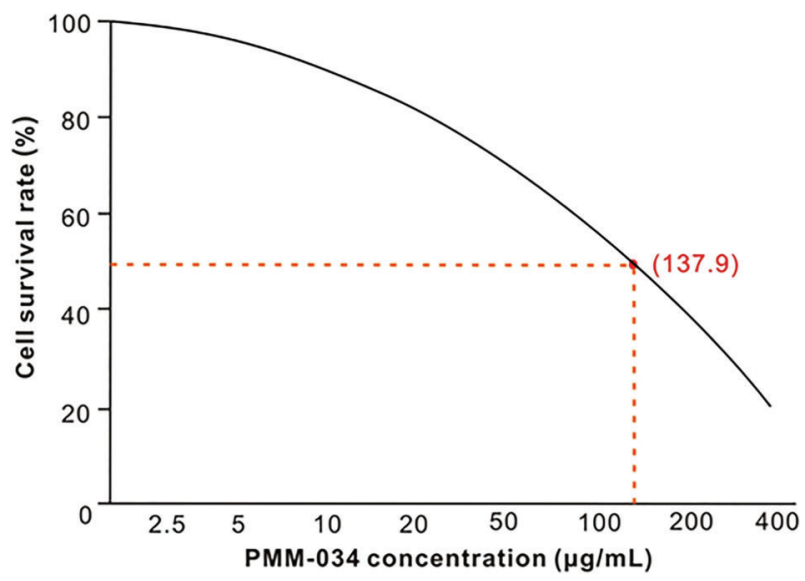

Figure 2. Cytotoxicity of shikonin ester derivative PMM-034 on rhabdomyosarcoma cell viability. PMM-034 was serially diluted to $0,2.5,5,10,20,50,100,200$, and $400 \mu \mathrm{g} / \mathrm{mL}$ in DMEM containing $2.5 \%$ FBS. Subsequently, the cytotoxicity of PMM-034 on RD cells was determined by the WST-1 assay. Data are reported as means \pm standard deviation (SD) from at least three independent experiments. The red dot indicates the PMM-034 concentration under $50 \%$ cell survival rate. 


\section{Dose- and time-dependent effects of PMM-034 on EV71 replication in RD cells}

The plaque reduction assay using culture supernatants showed inhibition rates of $54.9 \pm 1.4,67.9 \pm 1.7$, $79.8 \pm 3.1$, and $91.3 \pm 1.9 \%$, respectively, for the tested concentrations. The $50 \%$ inhibitory concentration $\left(\mathrm{IC}_{50}\right)$ of PMM-034 for EV71 replication was $2.31 \mu \mathrm{g} / \mathrm{mL}$. EV71 replication was not inhibited in EV71-infected RD cells treated with the same concentration of DMSO (Figure $3 \mathrm{~A}$ ). The result showed that PMM-034 exhibited strong antiviral activity against EV71 in a dose-dependent manner.

A time course assay was performed to explore the stages of the EV71 viral replication cycle that were affected by PMM-034. EV71 replication in RD cells was suppressed from $0-8 \mathrm{~h}$, whereas only a partial inhibitory effect was observed at 12-24 h (Figure 3B). Therefore, anti-EV71 activity of PMM-034 was most prominent when it was applied early in the EV71 replication cycle.

\section{PMM-034 reduced the mRNA and protein expressions of EV71 VP1}

To study how PMM-034 affected the mRNA and protein levels of EV71/NP1, total RNA was extracted from EV71-infected cells treated with or without PMM-034 for $24 \mathrm{~h}$. The results of the qRT-PCR revealed that EV71 VP1 mRNA level was significantly reduced in the PMM034-treated cells (Figure 4A). Consistent with these results, PMM-034 decreased the expression of VP1 protein (Figure 4B).
A

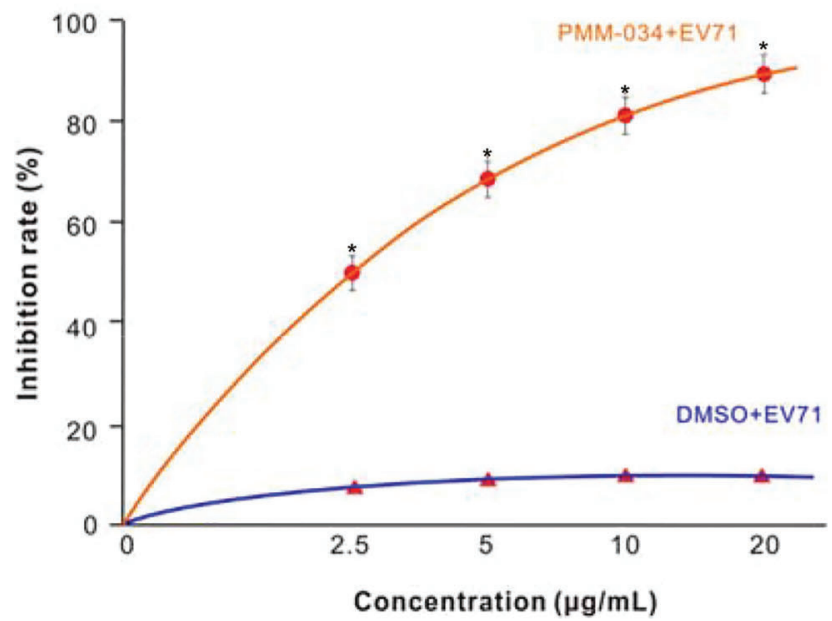

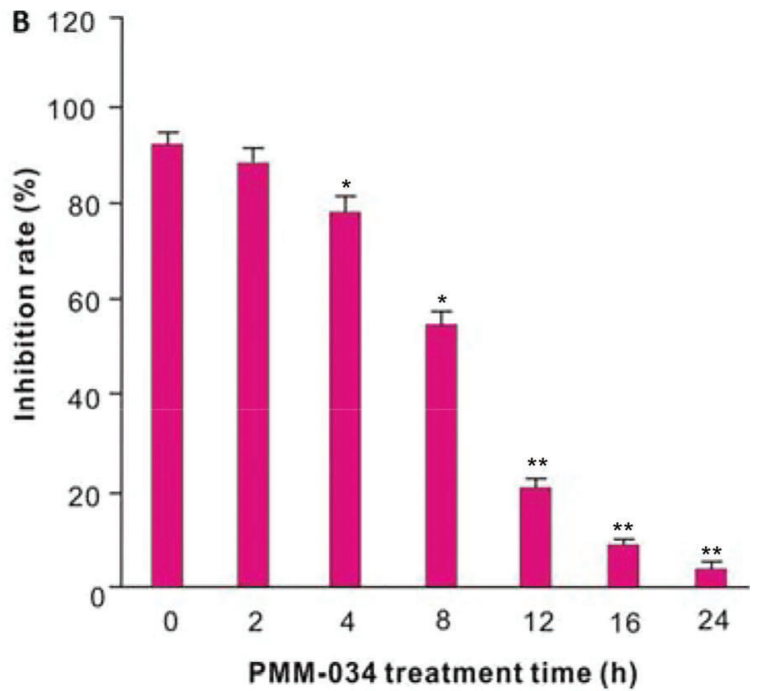

Figure 3. Dose- and time-dependent effects of PMM-034 on human enterovirus 71 (EV71) replication in rhabdomyosarcoma (RD) cells. $A, \mathrm{RD}$ cells were infected with EV71 for $1 \mathrm{~h}$, then treated with PMM-034 or DMSO for $23 \mathrm{~h}$. Infected cells and culture supernatants were collected $48 \mathrm{~h}$ post-infection. $B, \mathrm{RD}$ cells were infected with EV71 for $1 \mathrm{~h}$, and $10 \mu \mathrm{g} / \mathrm{mL} \mathrm{PMM-034}$ was added at $0,2,4,8,12,16$, and $24 \mathrm{~h}$ after infection. Virus titers were measured by the plaque reduction assay. Data are reported as means \pm SD from at least 3 independent experiments. ${ }^{*} \mathrm{P}<0.05 ;{ }^{*} \mathrm{P}<0.01$, Student's $t$-test.
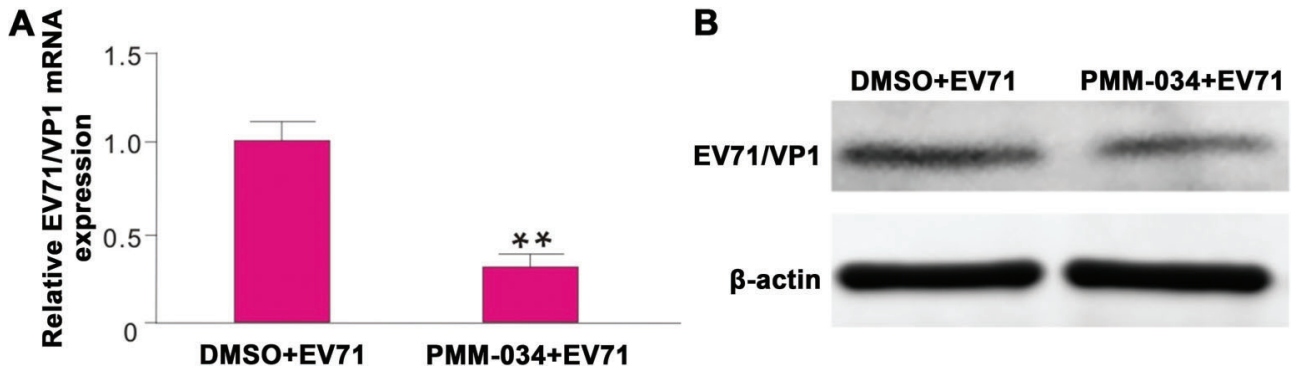

Figure 4. Effects of PMM-034 on human enterovirus 71 (EV71/NP1) mRNA and protein expressions in rhabdomyosarcoma (RD) cells. $\mathrm{RD}$ cells were infected with EV71 for $1 \mathrm{~h}$ and then treated with $10 \mu \mathrm{g} / \mathrm{mL}$ PMM-034 or DMSO for $23 \mathrm{~h}$. $A$, The EV71/VP1 mRNA level was detected by real-time RT-PCR. GAPDH was used as the internal control. Data are reported as means \pm SD of at least 3 independent experiments, ${ }^{* *} \mathrm{P}<0.01$, Student's $t$-test. $B$, Expression levels of EV71/VP1 protein were detected by western blotting. $\beta$-actin was used as the internal control. 


\section{PMM-034 reduced the severity of EV71-induced inflammation}

The TNF- $\alpha, \mathrm{IL}-1 \beta, \mathrm{IL}-6$, and IL-8 expression levels were significantly lower in EV71-infected RD cells treated with PMM-034 compared to DMSO-treated EV71-infected cells (Figure $5 \mathrm{~A}$ ).

Furthermore, PMM-034 decreased the phospho-p65 protein levels, which might account for the reduction of pro-inflammatory cytokines in EV71-infected RD cells treated with PMM-034 (Figure 5B).

\section{Discussion}

Certain TCMs have shown antiviral activity (24), and often function via multiple mechanisms of action and are associated with few side effects and no drug resistance (25). Lariciresinol-4-O- $\beta$-d-glucopyranoside, which is one of lignin compounds extracted from the root of Isatis indigotica, has been found to be effective against influenza A virus-induced CPE in MDCK cells. These studies also revealed that the lignin glycoside suppressed H1N1induced expression of the proinflammatory molecules IL-6, TNF- $\alpha$, IL-8, MCP- 1, IP-10, and IFN- $\alpha$ (26). Baicalin, a flavonoid compound extracted from Scutellaria roots, also exhibits potent antiviral effects on EV71 infection through inhibition of EV71/3D polymerase expression and Fas/FasL signaling pathways (27). Shikonin also possesses anti-AdV3 capabilities and the potential antiviral mechanism might involve inhibition of the degree of apoptosis and hexon protein expression of AdV (7). Recent research on shikonin has shifted to its derivatives, of which PMM-034 is one type. To date, it is still poorly understood whether shikonin can inhibit EV71 infection, let alone the antiviral activity of PMM-034 on EV71. In the present study, we found that $\leqslant 100 \mu \mathrm{g} / \mathrm{mL}$ PMM-034 was not cytotoxic to RD cells. We found that PMM-034 exhibited a strong antiviral effect against EV71, and could inhibit $54.9-91.3 \%$ of the virus in a concentration-dependent manner. Furthermore, the $\mathrm{IC}_{50}$ of this compound against EV71 was $2.31 \mu \mathrm{g} / \mathrm{mL}$. PMM-034 significantly suppressed EV71 replication in RD cells at $0-8 \mathrm{~h}$ after infection, but weakly inhibited replication at $12-24 \mathrm{~h}$ after infection. This indicates that the antiviral effects of PMM-034 occurred mainly at the early stage of EV71 infection.

The EV71 genome consists of a positive-sense single-stranded 7400-bp RNA (28). Upon infection, the internal ribosome entry site element in the $5^{\prime}$-untranslated region drives the translation of the viral processor polyprotein (29). This polyprotein, which is encoded as $\mathrm{NH}_{2}$-VP4-VP2-VP3-VP1-2A-2B-2C-3A-3B-3C-3D-COOH, is then proteolytically cleaved by viral $2 \mathrm{~A}$ and $3 \mathrm{C}$ proteases to form a range of viral structural proteins (VP1, VP2, VP3, and VP4) and 7 non-structural viral proteins (2A, 2B, 2C, 3A, 3B, 3C, and 3D) (30). The first three viral proteins (VP1-VP3) are present on the outer surface of the virus, and the shorter VP4 is located completely on the inner surface of the capsid. The capsid proteins initiate infection by binding to a receptor on the host membrane (31). VP1 is the most external and immunodominant of the picornavirus capsid proteins, and the VP1 sequence may
A
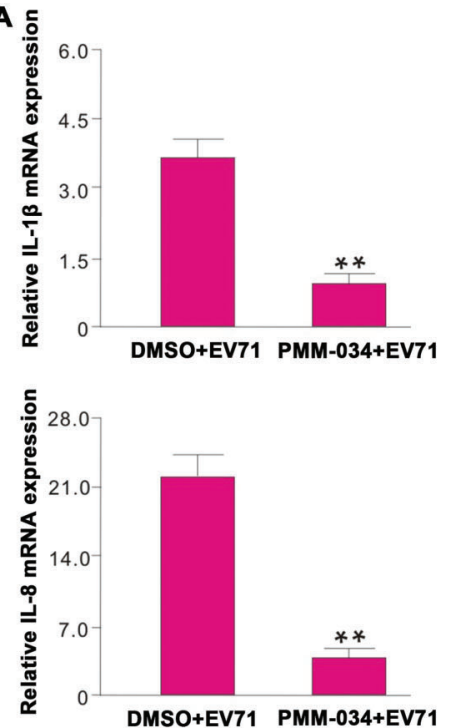

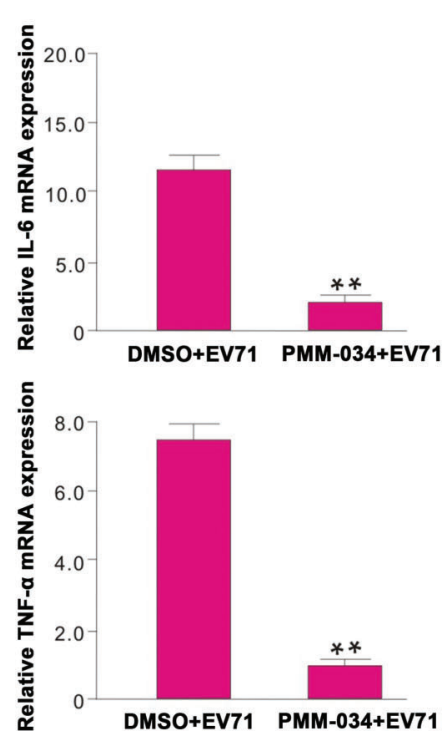

B

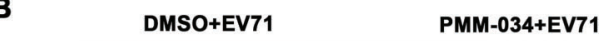

Figure 5. Effects of PMM-034 on the mRNA levels of pro-inflammatory cytokines and phospho-p65 protein expression in rhabdomyosarcoma (RD) cells. RD cells were infected with human enterovirus 71 (EV71) for $1 \mathrm{~h}$, then treated with $10 \mu \mathrm{g} / \mathrm{mL} \mathrm{PMM}-034$ or DMSO for $23 \mathrm{~h}$. $A$, mRNA levels of IL-1 $\beta$, IL-6, IL-8, and TNF- $\alpha$ were detected by real-time RT-PCR. GAPDH was used as the internal control. Data are reported as means $\pm \mathrm{SD}$ of at least 3 independent experiments. ${ }^{* *} \mathrm{P}<0.01$, Student's $t$-test. $B$, Phospho-p65 protein expression was detected by western blotting. $\beta$-actin was used as the internal control. 
be applied to classify enteroviruses and to analyze the phylogenetic relationships among human enteroviruses (32). VP1 has often been used for EV71 molecular genotyping and epidemiological monitoring (33). Here, we found that VP1 protein expression was significantly blocked by PMM-034 at the early stage of EV71 infection. Furthermore, EV71 mRNA abundance was also reduced after treatment with PMM-034, which was consistent with the results of the western blot analysis.

Previous studies have shown that the severity of clinical manifestations associated with EV71 infection possibly depend on the host immune inflammatory response, including pro-inflammatory and anti-inflammatory cytokines and chemokine storms in the blood and cerebrospinal fluid (34). Systemic inflammation caused by EV71 infection further deteriorated CNS disease, resulting in disease progression to the critical illness stage (35). NLRP3 inflammasomes have been shown to play a crucial role in the pathogenesis of coxsackievirus B3-induced myocarditis (36). Infection with CBV3, an enterovirus of the Piconaviridae family, induced production of IL-1 $\beta$ in cardiac tissues of VMC mice, which was positively correlated with the severity of myocarditis (37). Excessive host immune responses may play a critical role in the course of CVB3induced myocarditis (37). In addition, IAV-elicited NF-кB activity helps viral replication and spreading, and inhibition of IKK activity by the small molecule inhibitors BAY117085 and BAY11-7082 severely impaired IAV infection in human lung carcinoma cell lines (38). It is well known that active $N F-\kappa B$ is a transcription factor that induces hundreds of genes as part of an adjustment program to cope with the danger and stress signals leading to NF- $\mathrm{KB}$ activation. The target genes of NF- $\mathrm{BB}$ include regulators of inflammatory cytokines (e.g., IL-8) and cell survival, proliferation, and cell surface proteins (38). In this study, EV71 infection enhanced the expression of pro-inflammatory cytokines such as TNF- $\alpha$, IL-1 $\beta$, IL-6, and IL-8. We further showed that PMM-034 could suppress the

\section{References}

1. Chen S, Yang Y, Yan X, Chen J, Yu H, Wang W. Influence of vitamin $A$ status on the antiviral immunity of children with hand, foot and mouth disease. Clin Nutr 2012; 31: 543-548, doi: 10.1016/j.clnu.2011.12.005.

2. He Y, Ong KC, Gao Z, Zhao X, Anderson VM, McNutt MA, et al. Tonsillar crypt epithelium is an important extra-central nervous system site for viral replication in EV71 encephalomyelitis. Am J Pathol 2014; 184: 714-720, doi: 10.1016/ j.ajpath.2013.11.009.

3. $\mathrm{Yu} \mathrm{ZL}, \mathrm{Xu} \mathrm{JL}$. Research progress on the pathogenesis of EV71-induced neurogenic pulmonary edema. Hn Jornal of Mroology 2013; 1: R725.721.

4. Everts M, Cihlar T, Bostwick JR, Whitley RJ. Accelerating drug development: antiviral therapies for emerging viruses as a model. Annu Rev Pharmacol Toxicol 2017; 57: 155169, doi: 10.1146/annurev-pharmtox-010716-104533. phosphorylation of NF-kB/p65 induced by EV71 infection. Therefore, we propose that PMM-034 might reduce the severity of the inflammatory response involved in the inhibition of NF- $\mathrm{KB}$ activation. Researchers usually choose non-human primates like green monkeys, cynomolgus, rhesus, and mouse models to investigate the pathogenesis of EV71 infection. Arita and his group reported that neonatal mice are susceptible to EV71 infection, and the mice exhibited an age-dependent susceptibility to EV71 infection (39). Mice older than 14 days were resistant to infection with EV71 clinical isolates. Yu et al. reported that EV71 infected immunocompetent-ICR mice developed rear limb paralysis and neuropathologies in the brain stem and spinal cord before death. For 1 to 7 days, MP-26 M infections in BALB/c mice can lead to limb paralysis, and the viruses can be isolated from skeletal muscle, blood, brains, livers, spleens and hearts (40). In the next step, we may also use neonatal mice as animal models to further investigate the inhibition effect of PMM-034 on EV71 infection and the underlying mechanism.

In this study, we found that PMM-034 could effectively suppress the expression of pro-inflammatory cytokines in EV71-infected RD cells, and exhibit antiviral activity against EV71, as evidenced by the reduced VP1 mRNA and protein levels in PMM-034-treated cells. Additionally, PMM-034 was not found to exert significant cytotoxicity against $\mathrm{RD}$ cells, making it a promising candidate for further development as an EV71 inhibitor.

\section{Acknowledgments}

This research was supported by the Program for Changjiang Scholars and Innovative Research Team in University (IRT_14R27), the National Natural Science Foundation of China (\#31470384, \#31171161, and \#31670298), and the Fundamental Research Funds for the Central Universities (\#020814380002).
5. Razonable RR. Antiviral drugs for viruses other than human immunodeficiency virus. Mayo Clin Proc 2011; 86: 10091026, doi: $10.4065 / \mathrm{mcp} .2011 .0309$.

6. Gong X, Zhou J, Zhu W, Liu N, Li J, Li L, et al. Excessive proinflammatory cytokine and chemokine responses of human monocyte-derived macrophages to enterovirus 71 infection. BMC Infect Dis 2012; 12: 224, doi: 10.1186/14712334-12-224.

7. Wang C, Gao L, Jin Y, Cardona CJ, Xing Z. Regulation of host responses and viral replication by the mitogen-activated protein kinases in intestinal epithelial cells infected with Enterovirus 71. Virus Res 2015; 197: 75-84, doi: 10.1016/ j.virusres.2014.12.016.

8. Lin YL, Hu YC, Liang CC, Lin SY, Liang YC, Yuan HP, et al. Enterovirus-71 virus-like particles induce the activation and maturation of human monocyte-derived dendritic cells 
through TLR4 signaling. PLoS One 2014; 9: e111496, doi: 10.1371 /journal.pone.0111496.

9. Hsieh YJ, Yen MH, Chiang YW, Yeh CF, Chiang LC, Shieh $\mathrm{DE}$, et al. Gan-Lu-Siao-Du-yin, a prescription of traditional Chinese medicine, inhibited enterovirus 71 replication, translation, and virus-induced cell apoptosis. J Ethnopharmacol 2016; 185: 132-139, doi: 10.1016/j.jep.2016.03.034.

10. Esposito F, Carli I, Del Vecchio C, Xu L, Corona A, Grandi N, et al. Sennoside $A$, derived from the traditional chinese medicine plant Rheum L., is a new dual HIV-1 inhibitor effective on HIV-1 replication. Phytomedicine 2016; 23: 1383-1391, doi: 10.1016/j.phymed.2016.08.001.

11. Ji P, Chen C, Hu Y, Zhan Z, Pan W, Li R, et al. Antiviral activity of Paulownia tomentosa against enterovirus 71 of hand, foot, and mouth disease. Biol Pharm Bull 2015; 38: 1-6, doi: 10.1248/bpb.b14-00357.

12. Lin HY, Chen W, Shi J, Kong WY, Qi JL, Wang XM, et al. Design, synthesis and biological evaluation of cinnamic acyl shikonin derivatives. Chem Biol Drug Des 2013; 81: 275283, doi: $10.1111 /$ cbdd.12077.

13. Zhang M, Zhao H, Zhao Z, Yan H, Lv R, Cui L, et al. Rapid screening, identification, and purification of neuraminidase inhibitors from Lithospermum erythrorhizon Sieb.et Zucc. by ultrafiltration with HPLC-ESI-TOF-MS combined with semipreparative HPLC. J Sep Sci 2016; 39: 2097-2104, doi: 10.1002/jssc.201600087.

14. Baloch SK, Ma L, Xu GH, Bai LF, Zhao H, Tang CY, et al. A potent anticancer agent of shikonin derivative targeting tubulin. Chirality 2015; 27: 274-280, doi: 10.1002/ chir.22425.

15. Andujar I, Rios JL, Giner RM, Recio MC. Pharmacological properties of shikonin - a review of literature since 2002. Planta Med 2013; 79: 1685-1697, doi: 10.1055/s-00331350934.

16. Kourounakis AP, Assimopoulou AN, Papageorgiou VP, Gavalas A, Kourounakis PN. Alkannin and shikonin: effect on free radical processes and on inflammation - a preliminary pharmacochemical investigation. Arch Pharm 2002; 335: 262-266, doi: 10.1002/1521-4184(200208)335:6 < 262::AIDARDP262> 3.0.CO;2-Y.

17. Chen $X$, Yang L, Zhang N, Turpin JA, Buckheit RW, Osterling $\mathrm{C}$, et al. Shikonin, a component of chinese herbal medicine, inhibits chemokine receptor function and suppresses human immunodeficiency virus type 1. Antimicrob Agents Chemother 2003; 47: 2810-2816, doi: 10.1128/ AAC.47.9.2810-2816.2003.

18. Wang R, Yin R, Zhou W, Xu D, Li S. Shikonin and its derivatives: a patent review. Expert Opin Ther Pat 2012; 22: 977-997, doi: 10.1517/13543776.2012.709237.

19. Lin HY, Li ZK, Bai LF, Baloch SK, Wang F, Qiu HY, et al. Synthesis of aryl dihydrothiazol acyl shikonin ester derivatives as anticancer agents through microtubule stabilization. Biochem Pharmacol 2015; 96: 93-106, doi: 10.1016/ j.bcp.2015.04.021.

20. Lin H-Y, Han H-W, Bai L-F, Qiu H-Y, Yin D-Z, Qi J-L, et al. Design, synthesis and biological evaluation of shikonin thioglycoside derivatives: new anti-tubulin agents. RSC Adv 2014; 4: 49796-49805, doi: 10.1039/C4RA08810G.

21. Lu L, Qin A, Huang $H$, Zhou P, Zhang $C$, Liu N, et al. Shikonin extracted from medicinal Chinese herbs exerts anti-inflammatory effect via proteasome inhibition. Eur $J$ Pharmacol 2011; 658: 242-247, doi: 10.1016/j.ejphar.2011. 02.043 .

22. Lin CW, Wu CF, Hsiao NW, Chang CY, Li SW, Wan L, et al. Aloe-emodin is an interferon-inducing agent with antiviral activity against Japanese encephalitis virus and enterovirus 71. Int J Antimicrob Agents 2008; 32: 355-359, doi: 10.1016/ j.ijantimicag.2008.04.018.

23. Zhu W, Chiu LC, Ooi VE, Chan PK, Ang PO, Jr. Antiviral property and mode of action of a sulphated polysaccharide from Sargassum patens against herpes simplex virus type 2 . Int J Antimicrob Agents 2004; 24: 279-283, doi: 10.1016/ j.ijantimicag.2004.02.022.

24. Li Y, Ooi LS, Wang H, But PP, Ooi VE. Antiviral activities of medicinal herbs traditionally used in southern mainland China. Phytother Res 2004; 18: 718-722, doi: 10.1002/ ptr.1518.

25. Li T, Peng T. Traditional Chinese herbal medicine as a source of molecules with antiviral activity. Antiviral Res 2013; 97: 1-9, doi: 10.1016/j.antiviral.2012.10.006.

26. Li J, Zhou B, Li C, Chen Q, Wang Y, Li Z, et al. Lariciresinol4-O-beta-D-glucopyranoside from the root of Isatis indigotica inhibits influenza A virus-induced pro-inflammatory response. J Ethnopharmacol 2015; 174: 379-386, doi: 10.1016/j.jep. 2015.08.037.

27. Li X, Liu Y, Wu T, Jin Y, Cheng J, Wan C, et al. The antiviral effect of baicalin on enterovirus 71 in vitro. Viruses 2015; 7: 4756-4771, doi: 10.3390/v7082841.

28. Han JF, Cao RY, Tian X, Yu M, Qin ED, Qin CF. Producing infectious enterovirus type 71 in a rapid strategy. Virol $J$ 2010; 7: 116, doi: 10.1186/1743-422X-7-116.

29. Li X, Liu Y, Hou X, Peng H, Zhang L, Jiang $Q$, et al. Chlorogenic acid inhibits the replication and viability of enterovirus 71 in vitro. PLoS One 2013; 8: e76007, doi: 10.1371/journal.pone.0076007.

30. Hung HC, Chen TC, Fang MY, Yen KJ, Shih SR, Hsu JT, et al. Inhibition of enterovirus 71 replication and the viral 3D polymerase by aurintricarboxylic acid. J Antimicrob Chemother 2010; 65: 676-683, doi: 10.1093/jac/dkp502.

31. Lin JY, Chen TC, Weng KF, Chang SC, Chen LL, Shih SR. Viral and host proteins involved in picornavirus life cycle. J Biomed Sci 2009; 16: 103, doi: 10.1186/1423-0127-16-103.

32. Oberste MS, Maher K, Kilpatrick DR, Pallansch MA. Molecular evolution of the human enteroviruses: correlation of serotype with VP1 sequence and application to picornavirus classification. J Virol 1999; 73: 1941-1948.

33. Chong P, Hsieh SY, Liu CC, Chou AH, Chang JY, Wu SC, et al. Production of EV71 vaccine candidates. Hum Vaccin Immunother 2012; 8: 1775-1783, doi: 10.4161/hv.21739.

34. Huang HI, Weng KF, Shih SR. Viral and host factors that contribute to pathogenicity of enterovirus 71 . Future Microbiol 2012; 7: 467-479, doi: 10.2217/fmb.12.22.

35. Ye N, Gong X, Pang LL, Gao WJ, Zhang YT, Li XL, et al. Cytokine responses and correlations thereof with clinical profiles in children with enterovirus 71 infections. BMC Infect Dis 2015; 15: 225, doi: 10.1186/s12879-015-0965-1.

36. Wang $Y$, Gao B, Xiong S. Involvement of NLRP3 inflammasome in CVB3-induced viral myocarditis. Am J Physiol Heart Circ Physiol 2014; 307: H1438-H1447, doi: 10.1152/ajpheart. 00441.2014 
37. Mason JW. Myocarditis and dilated cardiomyopathy: an inflammatory link. Cardiovasc Res 2003; 60: 5-10, doi: 10.1016/S0008-6363(03)00437-1.

38. Schmitz ML, Kracht M, Saul VV. The intricate interplay between RNA viruses and NF-kappaB. Biochim Biophys Acta 2014; 1843: 2754-2764, doi: 10.1016/j.bbamcr.2014.08.004.

39. Arita M. Cooperative effect of the attenuation determinants derived from poliovirus sabin 1 strain is essential for attenuation of enterovirus 71 in the NOD/SCID mouse infection model. J Virol 2008; 82: 1787-1797, doi: 10.1128/ JVI.01798-07.

40. Yu CK, Chen CC, Chen CL, Wang JR, Liu CC, Yan JJ, et al. Neutralizing antibody provided protection against enterovirus type 71 lethal challenge in neonatal mice. J Biomed Sci 2000; 7: 523-528, doi: 10.1007/ BF02253368. 